\title{
In Situ Synthesis of a Magnetic Graphene Platform for the Extraction of Benzimidazoles from Food Samples and Analysis by High-Performance Liquid Chromatography
}

\author{
Qianchun Zhang, Yulan Liu, Xingyi Wang, Huimin Li, and Junyu Chen \\ School of Biology and Chemistry, Xingyi Normal University for Nationalities, Xingyi 562400, China \\ Correspondence should be addressed to Qianchun Zhang; qianchunzhang@qq.com
}

Received 10 February 2017; Accepted 12 April 2017; Published 4 May 2017

Academic Editor: Miguel de la Guardia

Copyright (C) 2017 Qianchun Zhang et al. This is an open access article distributed under the Creative Commons Attribution License, which permits unrestricted use, distribution, and reproduction in any medium, provided the original work is properly cited.

\begin{abstract}
A novel method was proposed for the determination of five benzimidazoles (oxfendazole, mebendazole, flubendazole, albendazole, and fenbendazole) using magnetic graphene $\left(\mathrm{G}-\mathrm{Fe}_{3} \mathrm{O}_{4}\right) \cdot \mathrm{G}-\mathrm{Fe}_{3} \mathrm{O}_{4}$ was synthesized via in situ chemical coprecipitation. The properties of $\mathrm{G}-\mathrm{Fe}_{3} \mathrm{O}_{4}$ were characterized by various instrumental methods. $\mathrm{G}-\mathrm{Fe}_{3} \mathrm{O}_{4}$ exhibited a great adsorption ability and good stability towards analytes. Various experimental parameters that might affect the extraction efficiency such as the amount of $\mathrm{G}-\mathrm{Fe}_{3} \mathrm{O}_{4}$, extraction solvent, extraction time, and desorption conditions were evaluated. Under the optimized conditions, a method based on $\mathrm{G}-\mathrm{Fe}_{3} \mathrm{O}_{4}$ magnetic solid-phase extraction coupled with high-performance liquid chromatography was developed. A good linear response was observed in the concentration range of $0.100-100 \mu \mathrm{g} / \mathrm{L}$ for the five benzimidazoles, with correlation coefficients ranging from 0.9966 to 0.9998 . The limits of detection $(S / N=3)$ of the method were between $17.2 \mathrm{and} 32.3 \mathrm{ng} / \mathrm{L}$. Trace benzimidazoles in chicken, chicken blood, and chicken liver samples were determined and the concentrations of oxfendazole, mebendazole, flubendazole, and fenbendazole in these samples were 13.0-20.2, 1.62-4.64, 1.94-6.42, and 0.292-1.04 ng/g, respectively. The recovery ranged from $83.0 \%$ to $115 \%$, and the relative standard deviations were less than $7.9 \%$. The proposed method was sensitive, reliable, and convenient for the analysis of trace benzimidazoles in food samples.
\end{abstract}

\section{Introduction}

Benzimidazoles (BMZs) are broad-spectrum anthelmintics and have been used in animal husbandry for the prevention and control of a wide variety of gastrointestinal nematodes in aquaculture, agriculture, and veterinary practices [1-4]. BMZs and their metabolites have been shown to cause teratogenic and embryotoxic effects in some species [5]. BMZs are difficult to degrade due to their high stability and complex molecular structures. As such, they are considered to be very significant food product pollutants. Due to the low concentration of the target compounds and the complex nature of their matrices, trace-level detection and identification as well as efficient sample preparation are critical. Therefore, the determination of BMZs in biological matrices remains a challenge. Towards this end, different preconcentration methods are necessary for the extraction of trace BMZs.

Sample preparation affects nearly all subsequent assay steps and is critical to the unequivocal identification, confirmation, and quantification of analytes [6]. To date, a number of sample preconcentration techniques have been reported for the isolation and enrichment of individual BMZs and their metabolites in food products prior to instrumental analysis. Various groups have reported methods to isolate and enrich BMZs by solid-phase extraction (SPE) $[7,8]$; some other methods and sample preconcentration techniques have been developed, including liquid-liquid extraction $[9,10]$, stir cake sorptive extraction [3], solid-phase microextraction (SPME) [11], ultrasound-assisted cloud-point extraction [12], supercritical fluid extraction [13], ultrasound-assisted emulsification-microextraction [14], QuEChERS [15], and 
ionic liquid-dispersive liquid-liquid microextraction [16]. However, in order to overcome the extensive time requirement and large volume of samples and toxic organic solvents, a new mode for SPE called magnetic solid-phase extraction (MSPE) was recently developed and has attracted significant attention in bioseparation and chemical analyses $[17,18]$. In MSPE, iron oxide materials are typically used as adsorbents and they possess some unique properties such as large surface areas, surface modifiability, excellent superparamagnetic propensity, and great biocompatibility. The development of magnetic solid-phase extraction (MSPE) overcomes the limitations of conventional SPE processes; in comparison with traditional SPE, MSPE is a modern and miniaturized technique which demands small volume of sample and solvents for easy clean-up procedures and also has other advantages, including the large interfacial area for mass transmission, easy operation, minimal time requirement, and amenability towards high throughput measurements [19-22]. The separation process in MSPE can be performed directly from a sample matrix containing a magnetic solid absorbent with the aid of an external magnet, without the need for additional centrifugation or filtration procedures, thus facilitating and simplifying the separation and collection processes. The aforementioned merits render MSPE a promising technique for sample preparation. To date, MSPE has been used in many fields [18, 23-27]. Notably, some research groups have utilized this method for the extraction of BMZs $[28,29]$.

In order to enhance the selectivity and extraction of MSPE, magnetic particles are usually subjected to surface functionalization with appropriate recognition molecules. $\mathrm{Fe}_{3} \mathrm{O}_{4}$ nanoparticles (NPS) are the most popular particles due to their low cost and toxicity. $\mathrm{Fe}_{3} \mathrm{O}_{4}$ NPS have been modified and functionalized with several different materials. Specifically, various research groups have functionalized the NPS with $\mathrm{C}_{8}$ [30], carbon nanotubes [31], polymers [32], and octadecyl moieties [33] and have used the modified $\mathrm{Fe}_{3} \mathrm{O}_{4}$ NPS to extract toxic substances and environmental pollutants from water and food. Among the aforementioned modified materials, graphene is a novel and interesting carbon-based material, it was discovered in 2004 by Novoselov et al. [34], and it has sparked remarkable interest in recent years [35, 36]. Graphene is a good candidate for the adsorption of benzenoid-like compounds because of its static superposition properties and specific large surface area. Zhang et al. described a new fabrication strategy for graphene-coated solid-phase microextraction fibres, which were utilized to enrich polycyclic aromatic hydrocarbons (PAHs) [37]. Wang and coworkers prepared a magnetic microsphere-confined graphene adsorbent, which was utilized in the extraction of PAHs from environmental water samples [38]. Zhao's group prepared graphene-coated magnetic NPS, which were utilized to extract triazine herbicides [23]. The solid-phase microextraction of BMZs by graphene oxide (GO)-bonded, fused-silica fibres has been reported [39]. Luo and coworkers synthesized a poly(ethylene glycol dimethacrylate)-graphene composite, which was used as stir rod sorptive extraction for the extraction of $16 \mathrm{BMZs}$ [40]; good extraction performance was achieved quickly and simply.
In this present study, magnetic graphene was synthesized by in situ chemical precipitation and was used as an adsorbent for the first time. Moreover, a novel analytical methodology based on $\mathrm{G}-\mathrm{Fe}_{3} \mathrm{O}_{4}$ MSPE coupled to HPLC was developed for the trace analysis of five BMZs, namely, oxfendazole, mebendazole, flubendazole, albendazole, and fenbendazole in chicken, chicken blood, and chicken liver samples.

\section{Experimental}

2.1. Chemicals and Materials. Graphite powder (50 mesh) was purchased from Boaixin Chemical Reagents (Baoding, China). Potassium permanganate $\left(\mathrm{KMnO}_{4}\right)$, concentrated sulphuric acid $\left(\mathrm{H}_{2} \mathrm{SO}_{4}\right)$, hydrogen peroxide $\left(\mathrm{H}_{2} \mathrm{O}_{2}\right)$, hydrochloric acid $(\mathrm{HCl})$, nitric acid $\left(\mathrm{HNO}_{3}\right)$, sodium nitrate $\left(\mathrm{NaNO}_{3}\right)$, all phosphate compounds, and all ammonium compounds were purchased from Tianjin Tianda Chemical Reagent Co. (Tianjin, China). Oxfendazole (OXF), mebendazole (MEB), flubendazole (FLU), albendazole (ALB), and fenbendazole (FEN) were purchased from Sigma (SigmaAldrich, USA). Stock standard solutions of BMZs in dimethyl sulfoxide/methanol $(1: 9, \mathrm{v} / \mathrm{v})(400 \mathrm{mg} / \mathrm{L})$ were prepared and were subsequently diluted. HPLC-grade acetonitrile was obtained from Tedia (Fairfield, OH, USA). Ultrapure water used throughout the experiments was obtained from a Milli$\mathrm{Q}$ gradient A10 system (Millipore, UK). All solutions were filtered through a $0.45-\mu \mathrm{m}$ filter before being injected into the LC system. All other reagents were of analytical grade.

2.2. Instruments. X-ray diffractometry (XRD) was carried out using a Rigaku diffractometer. The size and morphology of the $\mathrm{G}-\mathrm{Fe}_{3} \mathrm{O}_{4}$ were determined by scanning electron microscopy (SEM), which was conducted using a 4300 SEM instrument (HITACHI, Japan); Transmission electron microscopy (TEM) was carried out using a Philips Tecnai 10 TEM instrument (Philips, Netherlands). Fourier transform infrared (FT-IR) spectroscopy was carried out on a Nicolet Avatar 330. The magnetic properties were characterized using a Squid-based magnetometer from Quantum Design (San Diego, CA). Centrifugation during sample preparation was performed in a TGL-20LM-B centrifuge equipped with angular rotor $(12 \times 2.0 \mathrm{~mL})$ (Hunan Star Science Instruments Co. Ltd., China). A QL-901 Vortex (Kylin-bell Lab Instruments Co., Ltd., China) was used for preparing the samples. An Agilent 1200 series LC system equipped with a quaternary pump, autosampler, and VWD ultraviolet detector controlled by Chemstation software was used in all analyses.

2.3. Synthesis of Functional Graphene. GO was prepared from natural graphite powder, using a previously reported procedure [41, 42] with slight modifications; in brief, graphite powder was treated with a mixture of concentrated $\mathrm{H}_{2} \mathrm{SO}_{4}$, $\mathrm{P}_{2} \mathrm{O}_{5}$, and $\mathrm{K}_{2} \mathrm{~S}_{2} \mathrm{O}_{8}$ at $80^{\circ} \mathrm{C}$. Then, $115 \mathrm{~mL}$ of $\mathrm{H}_{2} \mathrm{SO}_{4}$ was added, and the mixture was cooled via immersion in an ice bath with stirring. Next, $5.0 \mathrm{~g}$ of $\mathrm{NaNO}_{3}$ was added to the mixture. Then, preoxidized graphite was added under vigorous stirring to avoid agglomeration. After the graphite powder was well dispersed, $15 \mathrm{~g}$ of $\mathrm{KMnO}_{4}$ was added slowly 
under stirring and the temperature was kept below $10^{\circ} \mathrm{C}$. The mixture was stirred at room temperature for $2 \mathrm{~h}$. As the reaction progressed, the mixture gradually started to become like a paste and the colour turned light brownish. Next, $230 \mathrm{~mL}$ of $\mathrm{H}_{2} \mathrm{O}$ was added slowly to the flask. The addition of water was performed in an ice bath to keep the temperature at $96^{\circ} \mathrm{C}$ for $1 \mathrm{~h}$. Then $30 \mathrm{~mL}$ of $30 \% \mathrm{H}_{2} \mathrm{O}_{2}$ was added to terminate the reaction. The resulting solution was allowed to stand overnight, centrifuged, and washed with a solution of $\mathrm{HCl}$ followed by water to remove metal ions until the $\mathrm{pH}$ was 7; the obtained brown dispersion was centrifuged at $3000 \mathrm{rpm}$ to remove any unexfoliated graphite oxide. Subsequently, it was dried to generate a brown solid, GO.

G- $\mathrm{Fe}_{3} \mathrm{O}_{4}$ was synthesized by the in situ chemical coprecipitation of $\mathrm{Fe}^{3+}$ and $\mathrm{Fe}^{2+}$ in an alkaline solution in the presence of GO. A solution of $\mathrm{NaOH} /$ diethylene glycol (DEG) $(10 \mathrm{mg} / \mathrm{mL})$ was prepared by adding $2.0 \mathrm{~g}$ sodium hydroxide to $200 \mathrm{~mL}$ of $\mathrm{DEG}$; the mixture was refluxed for $1 \mathrm{~h}$ at $120^{\circ} \mathrm{C}$ under a $\mathrm{N}_{2}$ atmosphere and then cooled to $70^{\circ} \mathrm{C}$. The magnetic composite was prepared by suspending $0.4 \mathrm{~g}$ GO in $250 \mathrm{~mL}$ of DEG, the mixture was ultrasonicated for $2 \mathrm{~h}$ and added to $1.6 \mathrm{~g}$ ferric chloride with stirring for $1 \mathrm{~h}$ at room temperature. Then, before rapidly injecting $67 \mathrm{~mL}$ of the $\mathrm{NaOH} / \mathrm{DEG}$ solution, it was heated at $220^{\circ} \mathrm{C}$ within $30 \mathrm{~min}$. After the product was cooled to room temperature, the precipitate was isolated using a magnetic field, and the supernatant was separated from the precipitate by decantation. The impurities in $\mathrm{G}-\mathrm{Fe}_{3} \mathrm{O}_{4}$ were removed by washing with water. $\mathrm{G}-\mathrm{Fe}_{3} \mathrm{O}_{4}$ was then washed with absolute alcohol until the green yellow colour disappeared. Subsequently, the composite was dried at $80^{\circ} \mathrm{C}$ for $24 \mathrm{~h}$ under vacuum.

2.4. Sample Preparation. The chicks were fed using $5 \mathrm{mg} / \mathrm{Kg}$ of BMZs in the corn for seven days. Then, they were slaughtered three days later. The thoroughly homogenized chicken, chicken blood, and chicken liver samples were prepared as follows: $5.0 \mathrm{~g}$ of the samples, $20 \mathrm{~mL}$ of ethyl acetate, $0.30 \mathrm{~mL}$ of a $25 \mathrm{~g} / 100 \mathrm{~mL}$ of $\mathrm{KOH}$ solution, and $0.50 \mathrm{~mL}$ of a $1 \mathrm{~g} / 100 \mathrm{~mL}$ butylated hydroxytoluene solution were mixed in a $50 \mathrm{~mL}$ Eppendorf vial. After the solution was sonicated for $5 \mathrm{~min}$, $0.50 \mathrm{~g} \mathrm{Na}_{2} \mathrm{SO}_{4}$ was added and was subjected to centrifugation at $16000 \mathrm{rpm}$. The resulting clear solution was placed in a $100 \mathrm{~mL}$ pear-shaped bottle. Next, the same solution was used to wash the homogenizer and the solution was thoroughly vortexed at room temperature for $2 \mathrm{~min}$, sonicated, and subjected to centrifugation again. Subsequently, the clear solution was added to the aforementioned pear-shaped bottle and dried at $40^{\circ} \mathrm{C}$ by a rotary evaporator. The residue was immediately dissolved in $10 \mathrm{~mL}$ of acetonitrile via ultrasonication, and $10 \mathrm{~mL}$ n-hexane was added. The acetonitrile solution was collected and dried via distillation under reduced pressure. Then, the residue was dissolved in $15.0 \mathrm{~mL}$ of water for the $\mathrm{G}-\mathrm{Fe}_{3} \mathrm{O}_{4}$ sorptive extraction. The concentrations of $\mathrm{BMZs}$ in the spiked sample solutions were $0.80 \mathrm{ng} / \mathrm{g}$ and $8.0 \mathrm{ng} / \mathrm{g}$.
2.5. MSPE Procedure. The MSPE procedure consisted of extraction, desorption, and HPLC analysis. First, $15.0 \mathrm{mg}$ of $\mathrm{G}-\mathrm{Fe}_{3} \mathrm{O}_{4}$ was rinsed with acetone and water and dispersed in $15.0 \mathrm{~mL}$ of the BMZ water sample solution. Secondly, the mixture was shaken for $30 \mathrm{~min}$ to extract the analytes. Subsequently, $\mathrm{G}-\mathrm{Fe}_{3} \mathrm{O}_{4}$ was isolated from the solution using a magnet placed at the bottom of the beaker; then, the supernatant was poured off. In order to completely remove the residual solution with a pipette, the particles were moved with a magnet, which was placed on the outside of the bottle wall. The isolated particles were then vortexed with $1.0 \mathrm{~mL}$ of acetic acid and methanol $(1: 99, \mathrm{v} / \mathrm{v})$ for $25 \mathrm{~min}$ to desorb the analytes. Afterwards, the magnet was placed on the bottom of the bottle and the desorption solution was collected with a micropipette and was subsequently dried with $\mathrm{N}_{2}$, to redissolve with $400 \mu \mathrm{L}$. Finally, $20.0 \mu \mathrm{L}$ was injected into the HPLC system for analysis. Prior to the next use, $\mathrm{G}_{-}-\mathrm{Fe}_{3} \mathrm{O}_{4}$ was washed twice with $5 \mathrm{~mL}$ of acetic acid and methanol (1:99, $\mathrm{v} / \mathrm{v})$ and $5 \mathrm{~mL}$ of acetone.

2.6. Chromatographic Operating Conditions. All chromatographic separation was performed on a Diamosil $\mathrm{C}_{18}(250 \times$ $4.6 \mathrm{~mm}$ i.d., $5 \mu \mathrm{m}$ ) column from Dikma (Beijing, China). The mobile phase used was acetonitrile/water $(\mathrm{pH} 3.0$ adjusted with $25 \mathrm{mmol} / \mathrm{L}$ of ammonium acetate and acetic acid). The acetonitrile phase was increased from 30\% to $70 \%$ during $0-20 \mathrm{~min}$. The flow rate of the mobile phase was $1.000 \mathrm{~mL} / \mathrm{min}$, and the wavelength used for ultraviolet detection was $295 \mathrm{~nm}$.

\section{Results and Discussion}

3.1. Morphological Structure of $\mathrm{G}_{-} \mathrm{Fe}_{3} \mathrm{O}_{4}$. X-ray diffraction (XRD) measurements were employed to investigate the structure of the synthesized samples; the graphite and G$\mathrm{Fe}_{3} \mathrm{O}_{4}$ patterns are shown in Figure 1(a). For graphite, the presence of the characteristic diffraction peak at ca. $26.5^{\circ}$, after the synthesis of $\mathrm{G}-\mathrm{Fe}_{3} \mathrm{O}_{4}$, due to $\mathrm{G}-\mathrm{Fe}_{3} \mathrm{O}_{4}$ was reduced to graphite and restored to the ordered crystal structure; the characteristic diffraction peak at ca. $26.5^{\circ}$ of graphite disappeared. This confirmed the successful oxidation of graphite [43]. Other diffraction peaks of $\mathrm{G}-\mathrm{Fe}_{3} \mathrm{O}_{4}$ appeared at $2 \theta=$ $30.1^{\circ}, 35.5^{\circ}, 43.1^{\circ}, 53.5^{\circ}, 57.0$, and $62.6^{\circ}$, which corresponded to crystal indexes of (2 200$),\left(\begin{array}{lll}3 & 1 & 1\end{array}\right),\left(\begin{array}{lll}4 & 0 & 0\end{array}\right),\left(\begin{array}{lll}4 & 2 & 2\end{array}\right),\left(\begin{array}{lll}5 & 1 & 1\end{array}\right)$, and $(440)$ of crystalline magnetite $\left(\mathrm{Fe}_{3} \mathrm{O}_{4}\right)$ [44]. $\mathrm{G}-\mathrm{Fe}_{3} \mathrm{O}_{4}$ displayed a similar pattern as that of crystalline magnetite $\left(\mathrm{Fe}_{3} \mathrm{O}_{4}\right)$.

The FT-IR spectra illustrated in Figure 1(b) revealed the chemical characteristic of the material. For $\mathrm{G}-\mathrm{Fe}_{3} \mathrm{O}_{4}$, stretching peak at $3430 \mathrm{~cm}^{-1}$ and the peak at $1471 \mathrm{~cm}^{-1}$ show the presence of $\mathrm{O}-\mathrm{H}$ groups. Characteristic stretching peaks of the epoxide functionality were observed at around $1190 \mathrm{~cm}^{-1}$, while that of the $\mathrm{C}=\mathrm{O}$ group was observed at $1568 \mathrm{~cm}^{-1}$. Overall, the FT-IR data confirmed that the reaction was successful.

The thermal stability of $\mathrm{G}-\mathrm{Fe}_{3} \mathrm{O}_{4}$ was investigated by thermogravimetric analysis (TGA). As shown in Figure 1(c), the curve revealed a weight loss event at $355^{\circ} \mathrm{C}$, prior to this 


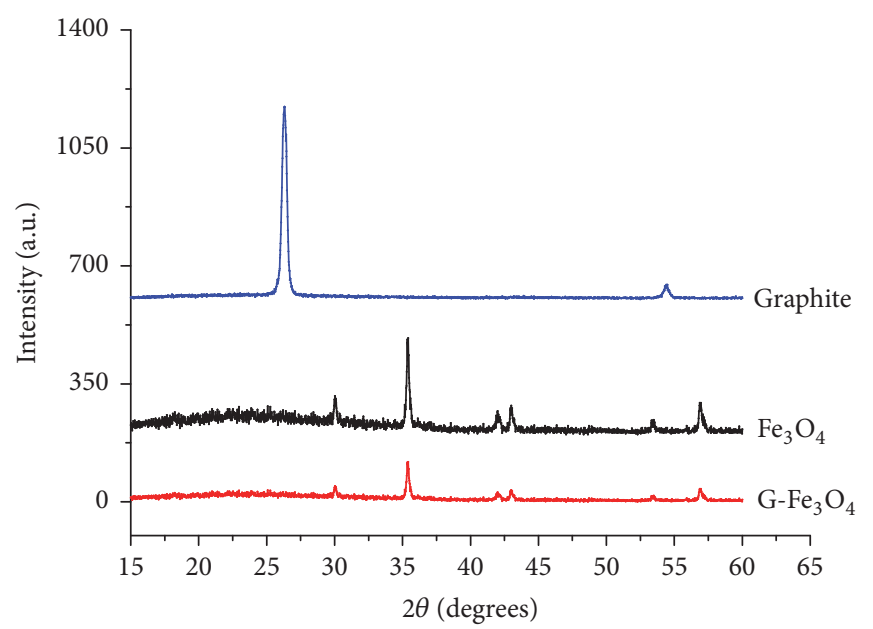

(a)

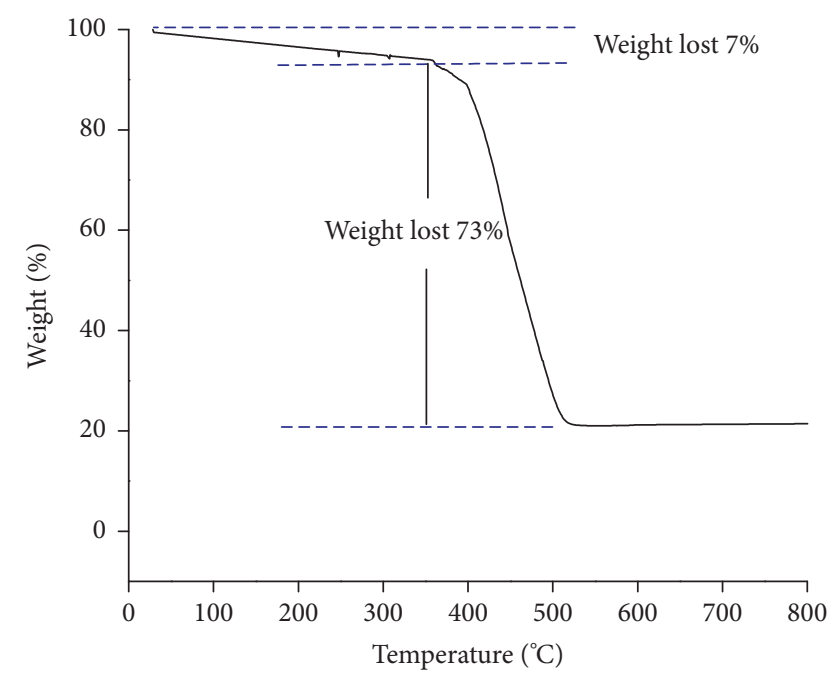

(c)

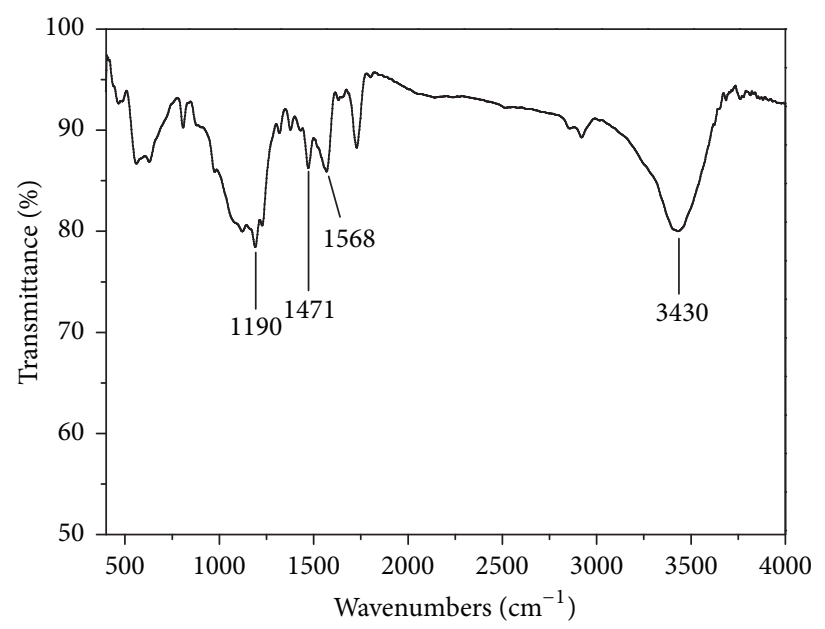

(b)

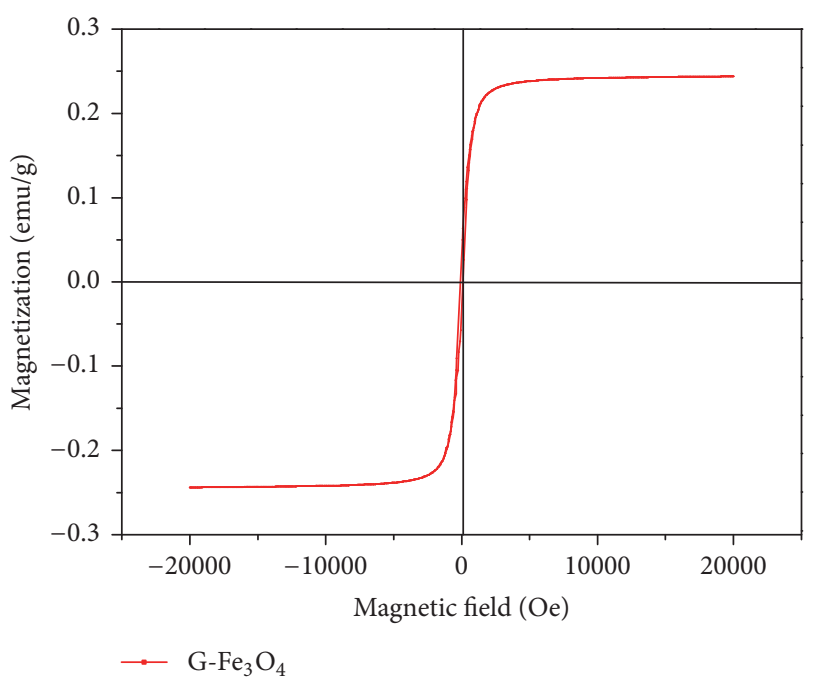

(d)

Figure 1: (a) X-ray diffraction (XRD) of graphite, $\mathrm{Fe}_{3} \mathrm{O}_{4}$, and $\mathrm{G}-\mathrm{Fe}_{3} \mathrm{O}_{4}$, (b) FT-IR spectra of $\mathrm{G}-\mathrm{Fe}_{3} \mathrm{O}_{4}$, (c) thermogravimetric analysis (TGA) of $\mathrm{G}-\mathrm{Fe}_{3} \mathrm{O}_{4}$, and (d) VSM magnetization curves of $\mathrm{G}-\mathrm{Fe}_{3} \mathrm{O}_{4}$.

temperature, the compound was stable. When the temperature was greater than $355^{\circ} \mathrm{C}$, the coordination structures and inorganic components decomposed the $\mathrm{Fe}_{3} \mathrm{O}_{4}$ graphene related to the collapse of the coordination structures and the decomposition of the inorganic components. However, since $\mathrm{G}-\mathrm{Fe}_{3} \mathrm{O}_{4}$ was synthesized at $220^{\circ} \mathrm{C}$, the compound exhibited high stability and could be obtained in a good yield.

$\mathrm{G}_{-} \mathrm{Fe}_{3} \mathrm{O}_{4}$ should possess sufficient magnetic properties to allow for rapid separation under a magnetic field. The VSM magnetization curves of $\mathrm{G}-\mathrm{Fe}_{3} \mathrm{O}_{4}$ at $25^{\circ} \mathrm{C}$ are shown in Figure 1(d); they indicated that $\mathrm{G}-\mathrm{Fe}_{3} \mathrm{O}_{4}$ exhibited excellent superparamagnetic behaviour. The saturation magnetization intensity of $\mathrm{G}-\mathrm{Fe}_{3} \mathrm{O}_{4}$ was $0.26 \mathrm{emu} \mathrm{g}^{-1}$. Therefore, $\mathrm{G}-\mathrm{Fe}_{3} \mathrm{O}_{4}$ can be used for magnetic separation from solution by using a strong magnet.

The TEM and SEM images of the $\mathrm{G}-\mathrm{Fe}_{3} \mathrm{O}_{4}$ composite are shown in Figure 2 and they illustrate the characteristic features of single-layer $\mathrm{G}$ sheets. It can be clearly seen that the carbon sheets resembled crumpled silk waves (Figure 2(b)). As shown in Figure 2(a), the iron oxide NPS were successfully coated on the surface of $\mathrm{G}$ to form the $\mathrm{G}-\mathrm{Fe}_{3} \mathrm{O}_{4}$ composite. The average size of the $\mathrm{Fe}_{3} \mathrm{O}_{4}$ NPS was about $5 \mathrm{~nm}$, as estimated by TEM. Moreover, the $\mathrm{Fe}_{3} \mathrm{O}_{4}$ NPS were well distributed on the graphene sheets, which were nearly flat and comprised a large area of up to several square micrometres. Because the loading degree was near saturation, some $\mathrm{Fe}_{3} \mathrm{O}_{4}$ NPS were slightly aggregated.

3.2. Effect of Extraction Conditions on Extraction Efficiency. The extract was based on $\pi-\pi$ interactions between the G$\mathrm{Fe}_{3} \mathrm{O}_{4}$ and the $\mathrm{BMZs}$. In order to determine the optimal extraction conditions, water spiked with an appropriate amount of BMZs was used to study the extraction performance under different experimental conditions. Several 


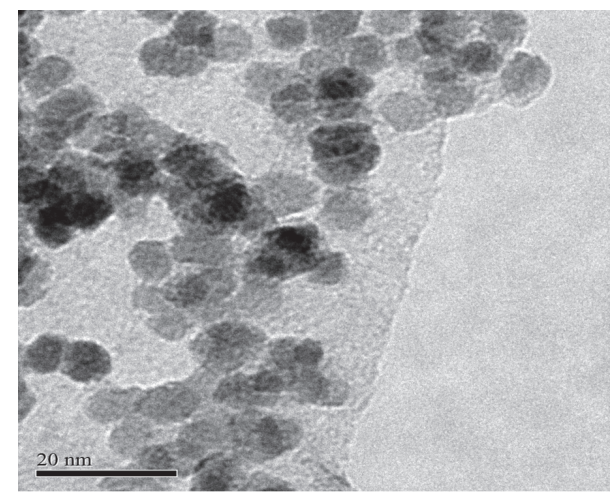

(a)

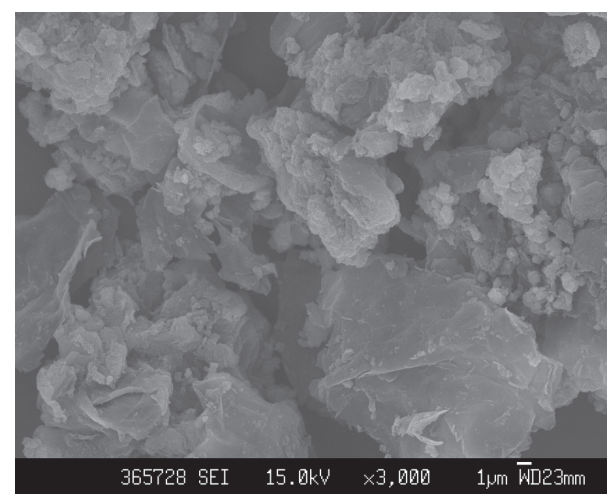

(b)

FIgURE 2: (a) TEM and (b) SEM images of $\mathrm{G}-\mathrm{Fe}_{3} \mathrm{O}_{4}$ composites.

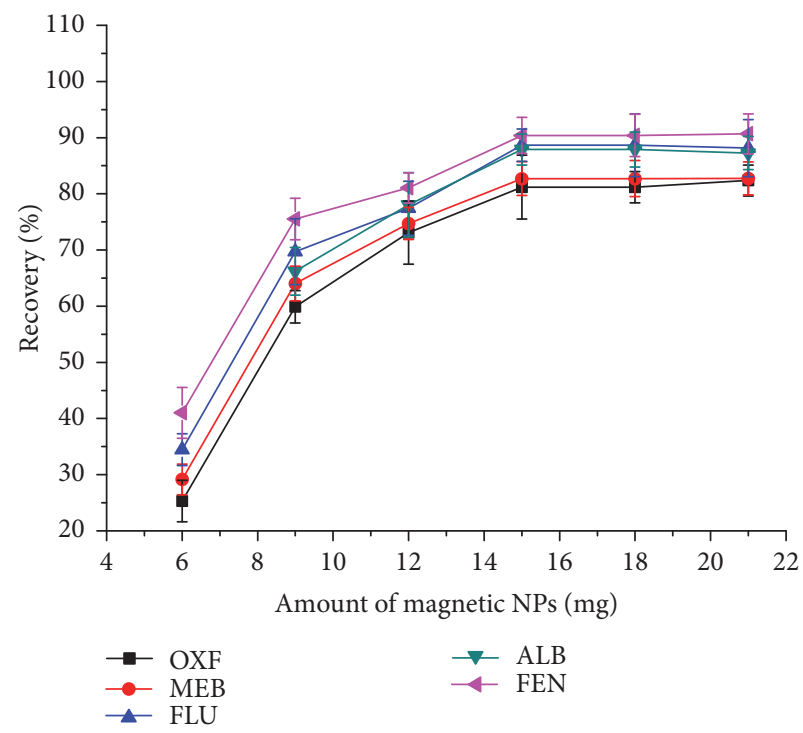

(a)

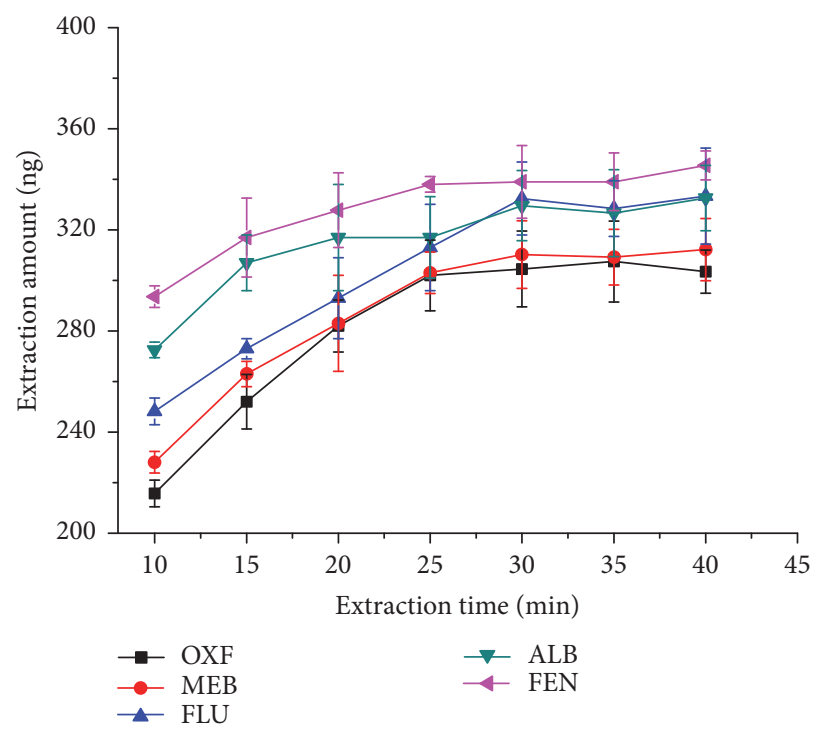

(b)

FIGURE 3: Effect of experimental conditions on the extraction efficiency. (a) Effect of the amount of sorbent and (b) effect of extraction time.

parameters, including the amount of $\mathrm{G}-\mathrm{Fe}_{3} \mathrm{O}_{4}$, extraction solvent, extraction time, and desorption conditions, were explored in order to achieve the best extraction efficiency. All experiments were performed in triplicate and the means of the results were reported.

3.2.1. Extraction Conditions. In order to determine the optimum amount of adsorbent $\left(\mathrm{G}-\mathrm{Fe}_{3} \mathrm{O}_{4}\right)$ for the extraction of BMZs (OXF, MEB, FLU, ALB, and FEN), the dosages of $\mathrm{G}-\mathrm{Fe}_{3} \mathrm{O}_{4}$ were varied from 6.0 to $21.0 \mathrm{mg}$. As shown in Figure 3(a), the maximum extraction efficiency was obtained with $15.0 \mathrm{mg}$ of $\mathrm{G}-\mathrm{Fe}_{3} \mathrm{O}_{4}$. When the amount of adsorbent was greater than $15.0 \mathrm{mg}$, the recovery was unchanged. Accordingly, $15.0 \mathrm{mg} \mathrm{G}-\mathrm{Fe}_{3} \mathrm{O}_{4}$ was selected as the optimal amount of adsorbent. Generally, in MSPE, sufficient contact time is required for the analytes to attain adsorption equilibrium on the sorbent. In order to elucidate the effects of extraction time on the adsorption efficiency of BMZs, the extraction time was varied from 10 to $40 \mathrm{~min}$, while other parameters were held constant; the results are shown in Figure 3(b). When the sample solutions were shaken for $30 \mathrm{~min}$, the extraction amounts of all BMZs were the greatest and remained almost content for extraction times greater than $30 \mathrm{~min}$; prolonged extraction times did not increase the extraction amount of the analytes significantly, indicating that the extraction equilibrium could be achieved in a short amount of time. Hence, an extraction time of $30 \mathrm{~min}$ was selected.

3.2.2. Desorption Conditions. The analytes should be completely desorbed from the $\mathrm{G}-\mathrm{Fe}_{3} \mathrm{O}_{4}$ particles prior to HPLC$\mathrm{UV}$ analysis. The desorption of BMZs required that the 


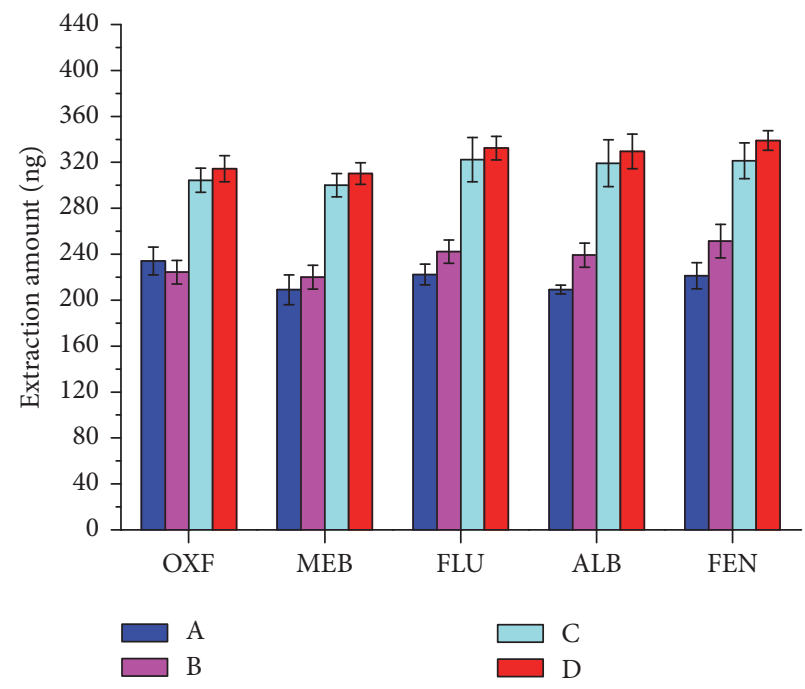

(a)

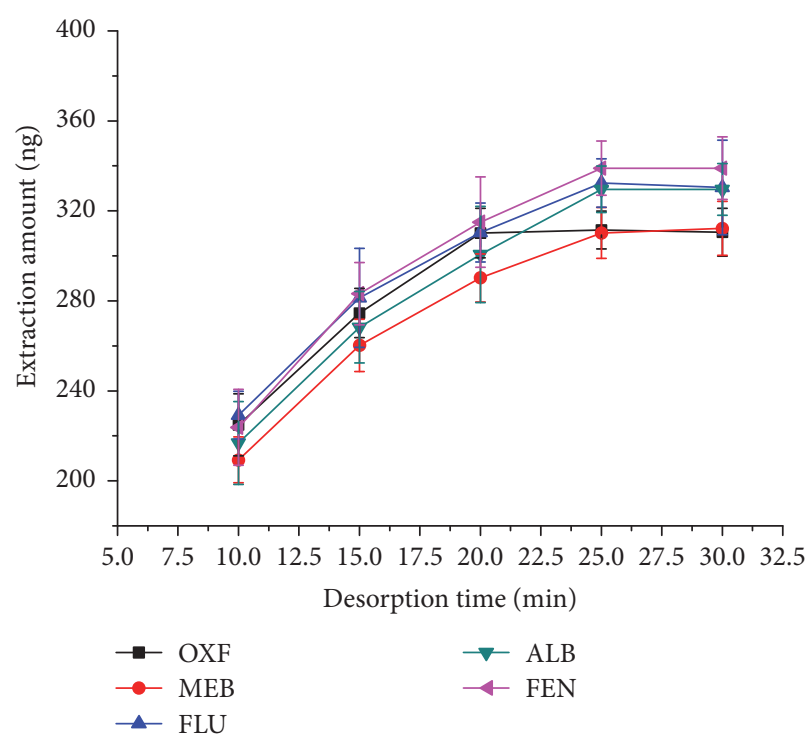

(b)

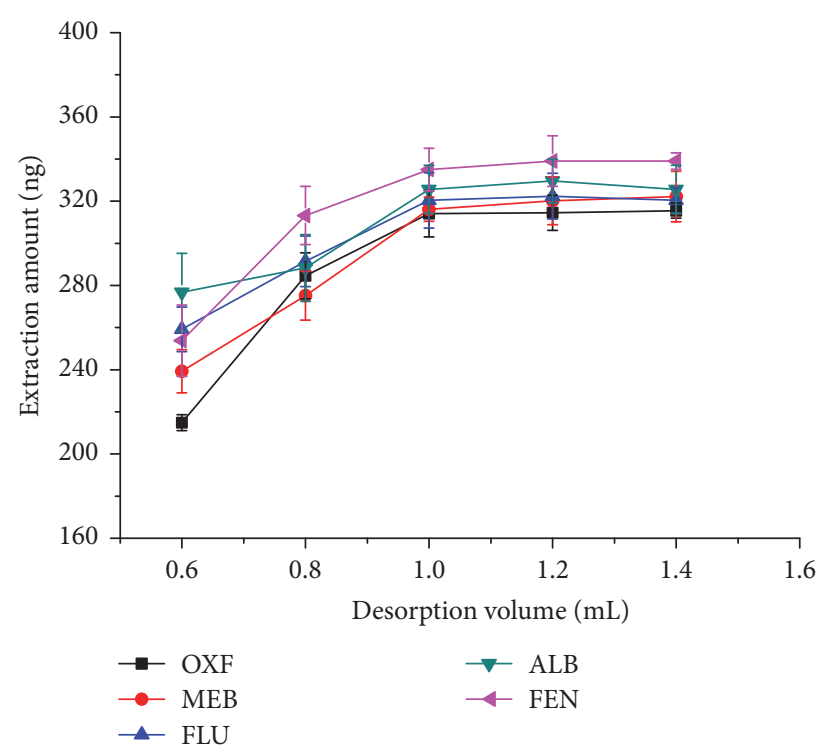

(c)

FIGURE 4: Effects of experimental conditions on the desorption efficiency. (a) Effects of desorption solvent, A: acetonitrile; B: methanol; C: acetic acid/acetonitrile $(1: 99, \mathrm{v} / \mathrm{v})$; D: acetic acid/methanol $(1: 99, \mathrm{v} / \mathrm{v}) ;(\mathrm{b})$ desorption time; and (c) volume of desorption solvent.

$\pi-\pi$ interactions be disrupted, so polar solvents were selected as the desorption solvents. In this work, the desorption of BMZs from $\mathrm{G}-\mathrm{Fe}_{3} \mathrm{O}_{4}$ was studied using different organic solvents, including acetonitrile, methanol, and mixtures of acetic acid and acetonitrile $(1: 99, \mathrm{v} / \mathrm{v})$ and acetic acid and methanol $(1: 99, \mathrm{v} / \mathrm{v})$. The results shown in Figure 4(a) reveal that, under the same extraction and elution conditions, the desorption power of acetic acid/methanol (1:99, v/v) and acetic acid/acetonitrile $(1: 99, \mathrm{v} / \mathrm{v})$ was much stronger than either methanol or acetonitrile; thus, matrix interferences were serious when using acetic acid/acetonitrile (1:99, v/v) solvent. Hence, it was selected as the desorption solvent. In addition, the influence of desorption time (from 10 to $30 \mathrm{~min}$ ) on the desorption efficiency of BMZs was investigated. In general, longer desorption times led to better extraction efficiencies, shown in Figure 4(b), and adsorption equilibrium was achieved after about $25 \mathrm{~min}$. Therefore, $25 \mathrm{~min}$ was ultimately chosen as the preferred desorption time. Under the optimized experimental conditions, the adsorbed analytes were desorbed with $0.60-1.40 \mathrm{~mL}$ acetic acid and methanol $(1: 99, \mathrm{v} / \mathrm{v})$ by vortexing for $25 \mathrm{~min}$ (Figure $4(\mathrm{c}))$. When $1.00 \mathrm{~mL}$ of the solvent was used, the analytes were almost 


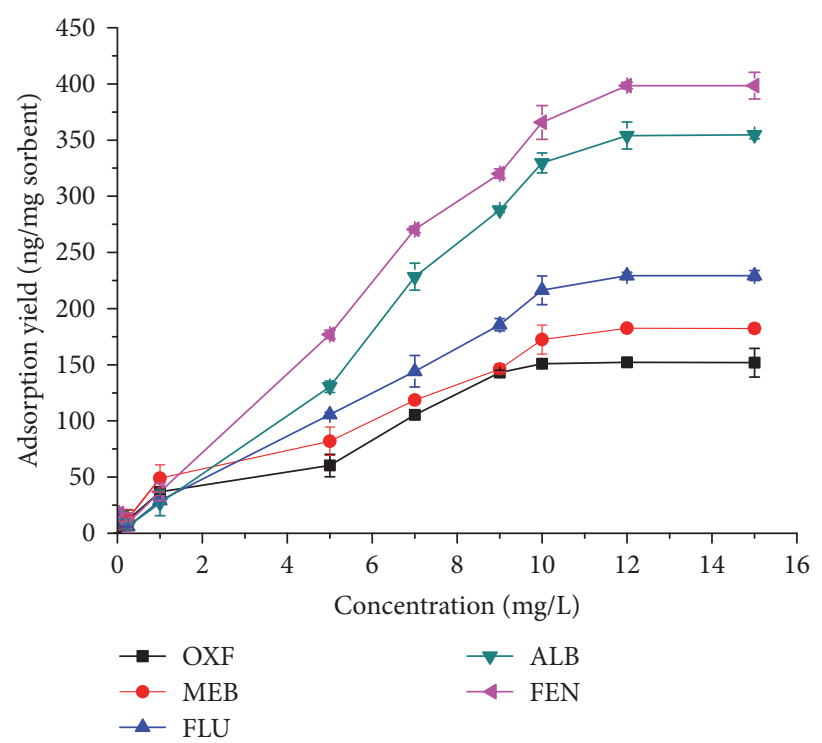

(a)

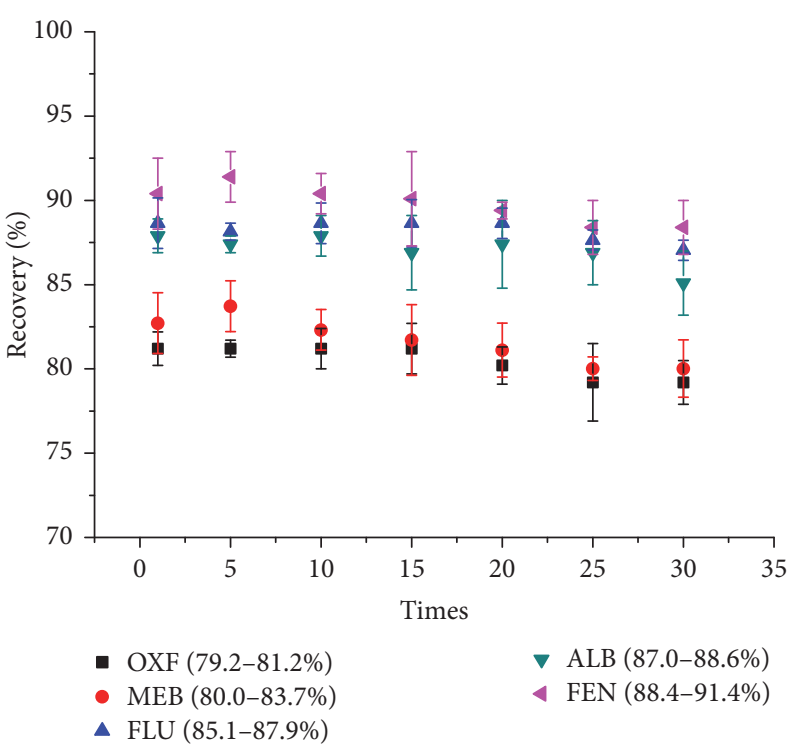

(b)

FIGURE 5: (a) Adsorption capacity of $\mathrm{G}-\mathrm{Fe}_{3} \mathrm{O}_{4}$ and (b) reusability of $\mathrm{G}-\mathrm{Fe}_{3} \mathrm{O}_{4}$ in the extraction of BMZs.

completely desorbed. Therefore, $1.00 \mathrm{~mL}$ of a mixture of acetic acid and methanol $(1: 99, \mathrm{v} / \mathrm{v})$ was used as the desorption solvent.

\subsection{Adsorption Performance of BMZs by $\mathrm{G}_{-} \mathrm{Fe}_{3} \mathrm{O}_{4}$}

3.3.1. Determination of $\mathrm{G}^{-\mathrm{Fe}_{3}} \mathrm{O}_{4}$ Adsorption Capacity. In this study, adsorption capacity was defined as the maximum amount of BMZs extracted by $\mathrm{G}-\mathrm{Fe}_{3} \mathrm{O}_{4}$. The $\mathrm{G}-\mathrm{Fe}_{3} \mathrm{O}_{4}$ sorbent was characterized in terms of capacity, which was directly related to the amount of graphene. The extraction capacity of the $\mathrm{G}-\mathrm{Fe}_{3} \mathrm{O}_{4}$ sorbent was determined by exposing the sorbent to water solutions containing increasing amounts of BMZs $(0.050-15.0 \mathrm{mg} / \mathrm{L})$ for $30 \mathrm{~min}$. The results are shown in Figure 5(a). The $\mathrm{G}-\mathrm{Fe}_{3} \mathrm{O}_{4}$ sorbent was able to extract up to $12 \mathrm{mg} / \mathrm{L}$ BMZs, and the amount of extracted BMZs reached a plateau at higher concentrations. The sorbent capacities were 152, 183, 229, 354, and $399 \mathrm{ng} \mathrm{BMZs} / \mathrm{mg}$ $\mathrm{G}-\mathrm{Fe}_{3} \mathrm{O}_{4}$ sorbent, respectively. The enrichment factors were measured as 114-299 for the selected five BMZs, indicating the remarkable preconcentration ability.

3.3.2. Reusability of the Sorbent. In order to investigate the reusability of the $\mathrm{G}-\mathrm{Fe}_{3} \mathrm{O}_{4}$ sorbent, it was washed twice with $5 \mathrm{~mL}$ of acetic acid and methanol (1:99, v/v) and $5 \mathrm{~mL}$ of acetone before it was reused in subsequent MSPE. The experimental results (Figure 5(b)) revealed that the G$\mathrm{Fe}_{3} \mathrm{O}_{4}$ sorbent could be reused at least 30 times without any significant loss of sorption capacity, and satisfied recovery with RSD $(n=5)$ lower than $9.6 \%$ was obtained on the extraction of five selected BMZs. This indicated that the iron oxide NPS were successfully coated on the surface of graphene in the $\mathrm{G}-\mathrm{Fe}_{3} \mathrm{O}_{4}$ composite, thus ensuring suitable stability during reuse.
3.4. Analytical Performance of MSPE. Under the optimized conditions, some analytical performance parameters of the method, including linear range (LR), correlation coefficient $\left(R^{2}\right)$, limit of detection (LOD), and limit of quantification (LOQ), were investigated.

3.4.1. Analytical Figures of Merit. A series of working solutions containing OXF, MEB, FLU, ALB, and FEN at concentrations ranging from 0.100 to $100 \mu \mathrm{g} / \mathrm{L}$ were prepared in order to establish the calibration curve. For each concentration, seven replicate extractions and determinations were performed under the optimized experimental conditions. The calibration data are listed in Table 1. Good linearity was observed over the concentration range of $0.100-100 \mu \mathrm{g} / \mathrm{L}$ for OXF, MEB, FLU, ALB, and FEN. The correlation coefficients ranged from 0.9966 to 0.9998 . The limits of detection (LODs) were within the range 17.2-32.3 ng/L (LODs were estimated on the basis of $3: 1$ signal to noise ratios). The resultant repeatability, expressed as relative standard deviation (RSD), varied from $3.4 \%$ to $7.6 \%$. The results indicated that the method was highly sensitive and reproducible.

3.4.2. Application of BMZs Analysis in Real Samples. The MSPE-HPLC method developed in this study was used to analyze several food samples, including chicken, chicken blood, and chicken liver samples. The MSPE showed maximal elimination of the matrix interferences and enhancement of the sensitivity. The amounts of OXF, MEB, FLU, and FEN in these samples ranged within 13.0-20.2, 1.62-4.64, 1.94-6.42, and $0.292-1.04 \mathrm{ng} / \mathrm{g}$, respectively. ALB was also detected in some samples; the results are shown in Table 2. To estimate the influence of the matrix all of the samples were spiked with different concentrations (Table 2). The satisfactory recoveries of the method ranged from $83.0 \%$ to $115 \%$ with RSDs between 
TABLE 1: Analytical performance and results for HPLC-UV determination of five BMZs using magnetic graphene.

\begin{tabular}{|c|c|c|c|c|c|c|}
\hline Compounds & Equation of linearity & $R^{2}$ & $\begin{array}{l}\text { Range } \\
(\mu \mathrm{g} / \mathrm{L})\end{array}$ & $\begin{array}{l}\mathrm{LOD}^{\mathrm{a}} \\
(\mathrm{ng} / \mathrm{L})\end{array}$ & $\begin{array}{l}\mathrm{LOQ}^{\mathrm{a}} \\
(\mathrm{ng} / \mathrm{L})\end{array}$ & $\begin{array}{c}\mathrm{RSD}^{\mathrm{b}} \\
(\%)(n=7)\end{array}$ \\
\hline OXF & $Y=9.31 \times 10^{4} X-6.4 \times 10^{2}$ & 0.9966 & $0.100-100$ & 19.4 & 58.7 & 3.4 \\
\hline MEB & $Y=7.62 \times 10^{4} X-9.6 \times 10^{2}$ & 0.9992 & $0.100-100$ & 28.3 & 84.6 & 5.7 \\
\hline FLU & $Y=7.26 \times 10^{4} X-7.9 \times 10^{2}$ & 0.9998 & $0.100-100$ & 27.4 & 82.8 & 7.6 \\
\hline ALB & $Y=6.45 \times 10^{4} X-1.1 \times 10^{3}$ & 0.9988 & $0.100-100$ & 32.3 & 97.4 & 5.4 \\
\hline FEN & $Y=1.01 \times 10^{5} X-8.4 \times 10^{2}$ & 0.9986 & $0.100-100$ & 17.2 & 52.2 & 4.9 \\
\hline
\end{tabular}

${ }^{\mathrm{a}} \mathrm{LOD}$ and LOQ were estimated on the basis of $3: 1$ and $10: 1$ signal to noise ratios, respectively.

${ }^{\mathrm{b}}$ The method precision was monitored with $1.0 \mu \mathrm{g} / \mathrm{L}$ mixed standard solution and the RSD of extraction amounts of five BMZs.

TABLE 2: Analysis of BMZs in food samples using the magnetic solid-phase extraction coupled to HPLC $(n=5)$.

\begin{tabular}{|c|c|c|c|c|c|c|c|}
\hline \multirow{3}{*}{ Samples } & \multirow{3}{*}{ Analytes } & \multirow{3}{*}{ Original amount (ng/g) } & \multirow{3}{*}{ RSD (\%) } & \multicolumn{4}{|c|}{ Spiked concentration (ng/g) } \\
\hline & & & & \multicolumn{2}{|c|}{$0.80 \mathrm{ng} / \mathrm{g}$} & \multicolumn{2}{|c|}{$8.0 \mathrm{ng} / \mathrm{g}$} \\
\hline & & & & Recovery (\%) & RSD (\%) & Recovery (\%) & RSD (\%) \\
\hline \multirow{5}{*}{ Chicken } & OXF & 13.0 & 3.9 & 84.1 & 4.2 & 94.8 & 3.4 \\
\hline & MEB & 3.00 & 7.2 & 83.0 & 4.9 & 105 & 3.4 \\
\hline & FLU & 4.56 & 6.2 & 84.8 & 5.9 & 105 & 5.1 \\
\hline & ALB & 0.450 & 6.3 & 89.6 & 5.8 & 107 & 4.8 \\
\hline & FEN & 1.04 & 8.7 & 84.7 & 7.9 & 92.4 & 6.4 \\
\hline \multirow{5}{*}{ Chicken blood } & OXF & 17.5 & 3.7 & 93.0 & 3.9 & 93.6 & 4.2 \\
\hline & MEB & 1.62 & 5.1 & 95.7 & 3.0 & 101 & 2.9 \\
\hline & FLU & 1.94 & 6.4 & 102 & 4.7 & 102 & 4.1 \\
\hline & ALB & N.Q. & - & 95.7 & 4.3 & 112 & 3.5 \\
\hline & FEN & 0.292 & 8.9 & 87.2 & 6.0 & 94.6 & 4.5 \\
\hline \multirow{5}{*}{ Chicken liver } & OXF & 20.2 & 3.5 & 85.9 & 4.2 & 90.9 & 3.5 \\
\hline & MEB & 4.64 & 5.6 & 88.7 & 5.1 & 115 & 4.3 \\
\hline & FLU & 6.42 & 4.3 & 91.8 & 3.4 & 108 & 2.7 \\
\hline & ALB & 0.342 & 5.7 & 97.8 & 3.9 & 112 & 3.4 \\
\hline & FEN & 1.01 & 6.9 & 95.0 & 4.0 & 97.3 & 3.6 \\
\hline
\end{tabular}

Note. N.Q.: not quantified.

$2.7 \%$ and $7.9 \%$ for chicken, chicken blood, and chicken liver samples, which suggested that the method was suitable for the analysis of the BMZs in complex samples. Typical chromatograms of BMZs from the samples are shown in Figure 6.

\section{Conclusion}

In the present study, $\mathrm{G}-\mathrm{Fe}_{3} \mathrm{O}_{4}$ was facilely synthesized by in situ chemical coprecipitation and it exhibited a great adsorption ability and good stability in the MSPE of BMZs. The proposed method for the determination of BMZs in chicken, chicken blood, and chicken liver samples was established by combining $\mathrm{G}-\mathrm{Fe}_{3} \mathrm{O}_{4}$ as an effective adsorbent with HPLCUV. The LODs were in the range of $17.2-32.3 \mathrm{ng} / \mathrm{L}$, and the recoveries of the method ranged between $83.0 \%$ and $115 \%$; the RSDs were less than 7.9\%. Furthermore, $\mathrm{G}-\mathrm{Fe}_{3} \mathrm{O}_{4}$ could be reused at least 30 times without a significant loss in the sorption capacity or magnetism. Moreover, the G$\mathrm{Fe}_{3} \mathrm{O}_{4}$ exhibited a remarkable preconcentration ability for five $\mathrm{BMZs}$, and satisfactory repeatability and recoveries were obtained. The use of $\mathrm{G}-\mathrm{Fe}_{3} \mathrm{O}_{4}$ was also faster and less expensive than other previously reported methods. The developed method serves as a simple and highly efficient extraction and preconcentration technique for BMZs in chicken, chicken blood, and chicken liver samples. MSPE based on the G$\mathrm{Fe}_{3} \mathrm{O}_{4}$ can also be used for the enrichment of other trace organic pollutants in food samples.

\section{Conflicts of Interest}

The authors declare that there are no conflicts of interest regarding the publication of this paper. 

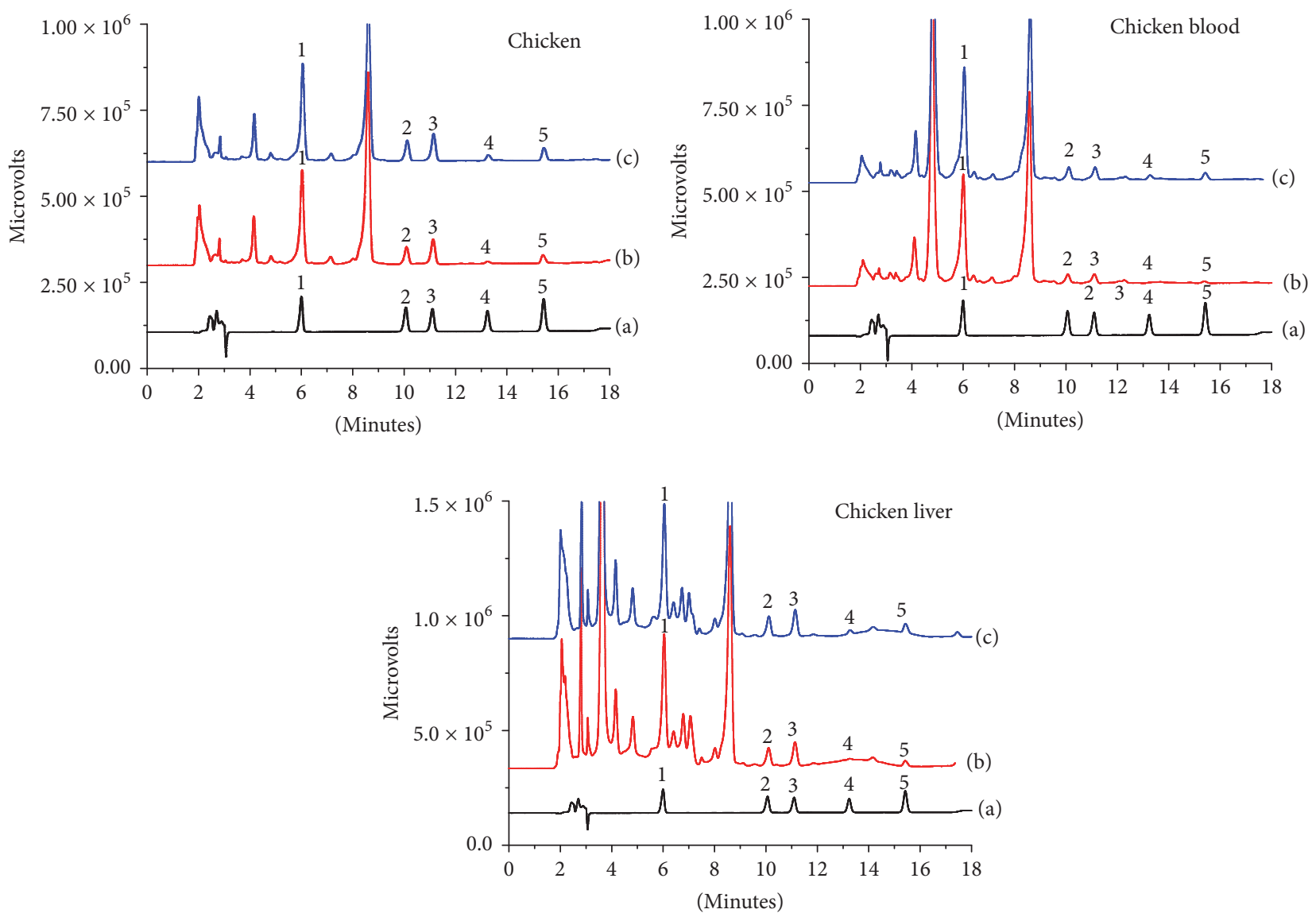

Figure 6: Chromatograms of BMZs in chicken, chicken blood, and chicken liver samples. (a) the standard solution at $1.0 \mathrm{mg} / \mathrm{L}$, (b) a sample solution extracted by G- $\mathrm{Fe}_{3} \mathrm{O}_{4} \mathrm{MSPE}$, and (c) $0.8 \mathrm{ng} / \mathrm{g}$ of the spiked sample solution extracted by G-Fe $\mathrm{O}_{4}$ MSPE. The peaks corresponded to the following BMZs: 1. OXF, 2. MEB, 3. FLU, 4. ALB, and 5. FEN.

\section{Acknowledgments}

The authors would like to thank the National Natural Science Foundation of China (no. 21505115) and the Science and Technology Foundation of the Guizhou Provincial Science and Technology Department (nos. LH20147406 and LH20167034).

\section{References}

[1] H. De Ruyck, R. Van Renterghem, H. De Ridder, and D. De Brabander, "Determination of anthelmintic residues in milk by high performance liquid chromatography," Food Control, vol. 11, no. 3, pp. 165-173, 2000.

[2] G. Balizs, "Determination of benzimidazole residues using liquid chromatography and tandem mass spectrometry," Journal of Chromatography B, vol. 727, no. 1-2, pp. 167-177, 1999.

[3] Y. Wang, J. Zhang, X. Huang, and D. Yuan, "Preparation of stir cake sorptive extraction based on polymeric ionic liquid for the enrichment of benzimidazole anthelmintics in water, honey and milk samples," Analytica Chimica Acta, vol. 840, pp. 33-41, 2014.

[4] J. Domínguez-álvarez, M. Mateos-Vivas, D. García-Gómez, E. Rodríguez-Gonzalo, and R. Carabias-Martínez, "Capillary electrophoresis coupled to mass spectrometry for the determination of anthelmintic benzimidazoles in eggs using a QuEChERS with preconcentration as sample treatment," Journal of Chromatography A, vol. 1278, pp. 166-174, 2013.

[5] O. Zamora, E. E. Paniagua, C. Cacho, L. E. Vera-Avila, and C. Perez-Conde, "Determination of benzimidazole fungicides in water samples by on-line MISPE-HPLC," Analytical and Bioanalytical Chemistry, vol. 393, no. 6-7, pp. 1745-1753, 2009.

[6] K. D. Clark, C. Zhang, and J. L. Anderson, "Sample preparation for bioanalytical and pharmaceutical analysis," Analytical Chemistry, vol. 88, no. 23, pp. 11262-11270, 2016.

[7] G. Caprioli, G. Cristalli, R. Galarini et al., "Comparison of two different isolation methods of benzimidazoles and their metabolites in the bovine liver by solid-phase extraction and liquid chromatography-diode array detection," Journal of Chromatography A, vol. 1217, no. 11, pp. 1779-1785, 2010.

[8] D. Chen, Y. Tao, H. Zhang et al., "Development of a liquid chromatography-tandem mass spectrometry with pressurized liquid extraction method for the determination of benzimidazole residues in edible tissues," Journal of Chromatography B, vol. 879, no. 19, pp. 1659-1667, 2011.

[9] M. Whelan, B. Kinsella, A. Furey et al., "Determination of anthelmintic drug residues in milk using ultra high performance liquid chromatography-tandem mass spectrometry with rapid polarity switching," Journal of Chromatography A, vol. 1217, no. 27, pp. 4612-4622, 2010. 
[10] L. Moreno, F. Imperiale, L. Mottier, L. Alvarez, and C. Lanusse, "Comparison of milk residue profiles after oral and subcutaneous administration of benzimidazole anthelmintics to dairy cows," Analytica Chimica Acta, vol. 536, no. 1-2, pp. 91-99, 2005.

[11] Y. Ji, X. Liu, X. Jiang et al., "Oxidized multiwalled carbon nanotubes as an SPME Fiber coating for rapid LC-UV analysis of benzimidazole fungicides in water," Chromatographia, vol. 70, no. 5-6, pp. 753-759, 2009.

[12] Y. Santaladchaiyakit and S. Srijaranai, "A simplified ultrasoundassisted cloud-point extraction method coupled with high performance liquid chromatography for residue analysis of benzimidazole anthelmintics in water and milk samples," Analytical Methods, vol. 4, no. 11, pp. 3864-3873, 2012.

[13] M. Danaher, M. O’Keeffe, and J. D. Glennon, “Development and optimisation of a method for the extraction of benzimidazoles from animal liver using supercritical carbon dioxide," Analytica Chimica Acta, vol. 483, no. 1-2, pp. 313-324, 2003.

[14] Y. Santaladchaiyakit and S. Srijaranai, "Preconcentration and Simultaneous Analysis of Benzimidazole Anthelmintics in Milk Samples by Ultrasound-Assisted Surfactant-Enhanced Emulsification Microextraction and High-Performance Liquid Chromatography," Food Analytical Methods, vol. 6, no. 6, pp. 1551-1560, 2013.

[15] J. Keegan, M. Whelan, M. Danaher et al., "Benzimidazole carbamate residues in milk: detection by Surface Plasmon Resonance-biosensor, using a modified QuEChERS (Quick, Easy, Cheap, Effective, Rugged and Safe) method for extraction," Analytica Chimica Acta, vol. 654, no. 2, pp. 111-119, 2009.

[16] M. Asensio-Ramos, J. Hernández-Borges, T. M. Borges-Miquel, and M. Á. Rodríguez-Delgado, "Ionic liquid-dispersive liquidliquid microextraction for the simultaneous determination of pesticides and metabolites in soils using high-performance liquid chromatography and fluorescence detection," Journal of Chromatography A, vol. 1218, no. 30, pp. 4808-4816, 2011.

[17] Q. Ye, L. Liu, Z. Chen, and L. Hong, "Analysis of phthalate acid esters in environmental water by magnetic graphene solid phase extraction coupled with gas chromatography-mass spectrometry," Journal of Chromatography A, vol. 1329, pp. 2429, 2014.

[18] M. Wierucka and M. Biziuk, "Application of magnetic nanoparticles for magnetic solid-phase extraction in preparing biological, environmental and food samples," Trends in Analytical Chemistry, vol. 59, pp. 50-58, 2014.

[19] Y. Ma, J. Xie, J. Jin et al., "Development of a magnetic solid-phase extraction coupled with high-performance liquid chromatography method for the analysis of polyaromatic hydrocarbons," Journal of Separation Science, vol. 38, no. 14, pp. 2517-2525, 2015.

[20] I. S. Ibarra, J. A. Rodriguez, J. M. Miranda, M. Vega, and E. Barrado, "Magnetic solid phase extraction based on phenyl silica adsorbent for the determination of tetracyclines in milk samples by capillary electrophoresis," Journal of Chromatography A, vol. 1218, no. 16, pp. 2196-2202, 2011.

[21] Q. Gao, D. Luo, J. Ding, and Y.-Q. Feng, "Rapid magnetic solidphase extraction based on magnetite/silica/poly(methacrylic acid-co-ethylene glycol dimethacrylate) composite microspheres for the determination of sulfonamide in milk samples," Journal of Chromatography A, vol. 1217, no. 35, pp. 5602-5609, 2010.

[22] A. Mehdinia, N. Khodaee, and A. Jabbari, "Fabrication of graphene/Fe3O4@polythiophene nanocomposite and its application in the magnetic solid-phase extraction of polycyclic aromatic hydrocarbons from environmental water samples," Analytica Chimica Acta, vol. 868, pp. 1-9, 2015.

[23] G. Zhao, S. Song, C. Wang, Q. Wu, and Z. Wang, "Determination of triazine herbicides in environmental water samples by high-performance liquid chromatography using graphenecoated magnetic nanoparticles as adsorbent," Analytica Chimica Acta, vol. 708, no. 1-2, pp. 155-159, 2011.

[24] R. D. Ambashta and M. Sillanpää, "Water purification using magnetic assistance: a review," Journal of Hazardous Materials, vol. 180, no. 1-3, pp. 38-49, 2010.

[25] C. Herrero-Latorre, J. Barciela-García, S. García-Martín, R. M. Peña-Crecente, and J. Otárola-Jiménez, "Magnetic solidphase extraction using carbon nanotubes as sorbents: a review," Analytica Chimica Acta, vol. 892, Article ID 234070, pp. 10-26, 2015.

[26] Q. Zhang, G. Li, X. Xiao, S. Zhan, and Y. Cao, "Efficient and selective enrichment of ultratrace cytokinins in plant samples by magnetic perhydroxy-cucurbit[8] uril microspheres," Analytical Chemistry, vol. 88, no. 7, pp. 4055-4062, 2016.

[27] J. Płotka-Wasylka, N. Szczepańska, M. de la Guardia, and J. Namieśnik, "Modern trends in solid phase extraction: new sorbent media," TrAC_-Trends in Analytical Chemistry, vol. 77, pp. 23-43, 2016.

[28] X.-Z. Hu, M.-L. Chen, Q. Gao, Q.-W. Yu, and Y.-Q. Feng, "Determination of benzimidazole residues in animal tissue samples by combination of magnetic solid-phase extraction with capillary zone electrophoresis," Talanta, vol. 89, pp. 335341, 2012.

[29] X. Deng, X. Chen, K. Lin, G. Ding, and P. Yao, "Rapid and selective determination of trace benzimidazole fungicides in fruit juices by magnetic solid-phase extraction coupled with high-performance liquid chromatography-fluorescence detection," Food Analytical Methods, vol. 6, no. 6, pp. 1576-1582, 2013.

[30] D. Song, Y. Gu, L. Liang, Z. Ai, L. Zhang, and H. Xu, "Magnetic solid-phase extraction followed by high performance liquid chromatography for determination of hexanal and heptanal in human urine," Analytical Methods, vol. 3, no. 6, pp. 1418-1423, 2011.

[31] J. Ding, Q. Gao, X.-S. Li, W. Huang, Z.-G. Shi, and Y.-Q. Feng, "Magnetic solid-phase extraction based on magnetic carbon nanotube for the determination of estrogens in milk," Journal of Separation Science, vol. 34, no. 18, pp. 2498-2504, 2011.

[32] Q. Gao, C.-Y. Lin, D. Luo, L.-L. Suo, J.-L. Chen, and Y.Q. Feng, "Magnetic solid-phase extraction using magnetic hypercrosslinked polymer for rapid determination of illegal drugs in urine," Journal of Separation Science, vol. 34, no. 21, pp. 3083-3091, 2011.

[33] C. Jiang, Y. Sun, X. Yu et al., "Removal of sudan dyes from water with C 18-functional ultrafine magnetic silica nanoparticles," Talanta, vol. 89, pp. 38-46, 2012.

[34] K. S. Novoselov, A. K. Geim, S. V. Morozov et al., "Electric field in atomically thin carbon films," Science, vol. 306, no. 5696, pp. 666-669, 2004.

[35] Z. Liu, Y. Wang, R. Deng et al., “Fe3O4@Graphene Oxide@Ag particles for surface magnet solid-phase extraction surfaceenhanced raman scattering (SMSPE-SERS): from sample pretreatment to detection all-in-one," ACS Applied Materials and Interfaces, vol. 8, no. 22, pp. 14160-14168, 2016.

[36] X. Chen, X. Hai, and J. Wang, "Graphene/graphene oxide and their derivatives in the separation/isolation and preconcentration of protein species: a review," Analytica Chimica Acta, vol. 922, pp. 1-10, 2016. 
[37] S. Zhang, Z. Du, and G. Li, "Layer-by-layer fabrication of chemical-bonded graphene coating for solid-phase microextraction," Analytical chemistry, vol. 83, no. 19, pp. 7531-7541, 2011.

[38] W. Wang, R. Ma, Q. Wu, C. Wang, and Z. Wang, "Magnetic microsphere-confined graphene for the extraction of polycyclic aromatic hydrocarbons from environmental water samples coupled with high performance liquid chromatographyfluorescence analysis," Journal of Chromatography A, vol. 1293, pp. 20-27, 2013.

[39] L. Xu, J. Feng, J. Li, X. Liu, and S. Jiang, "Graphene oxide bonded fused-silica fiber for solid-phase microextraction-gas chromatography of polycyclic aromatic hydrocarbons in water," Journal of Separation Science, vol. 35, no. 1, pp. 93-100, 2012.

[40] Y.-B. Luo, J.-S. Cheng, Q. Ma, Y.-Q. Feng, and J.-H. Li, "Graphene-polymer composite: extraction of polycyclic aromatic hydrocarbons from water samples by stir rod sorptive extraction," Analytical Methods, vol. 3, no. 1, pp. 92-98, 2011.

[41] W. S. Hummers Jr. and R. E. Offeman, "Preparation of graphitic oxide," Journal of the American Chemical Society, vol. 80, no. 6, p. 1339, 1958.

[42] D. Li, M. B. Müller, S. Gilje, R. B. Kaner, and G. G. Wallace, "Processable aqueous dispersions of graphene nanosheets," Nature Nanotechnology, vol. 3, no. 2, pp. 101-105, 2008.

[43] M. J. McAllister, J.-L. Li, D. H. Adamson et al., "Single sheet functionalized graphene by oxidation and thermal expansion of graphite," Chemistry of Materials, vol. 19, no. 18, pp. 4396-4404, 2007.

[44] Y.-H. Deng, C.-C. Wang, J.-H. Hu, W.-L. Yang, and S.-K. Fu, "Investigation of formation of silica-coated magnetite nanoparticles via sol-gel approach," Colloids and Surfaces A: Physicochemical and Engineering Aspects, vol. 262, no. 1-3, pp. 87-93, 2005. 

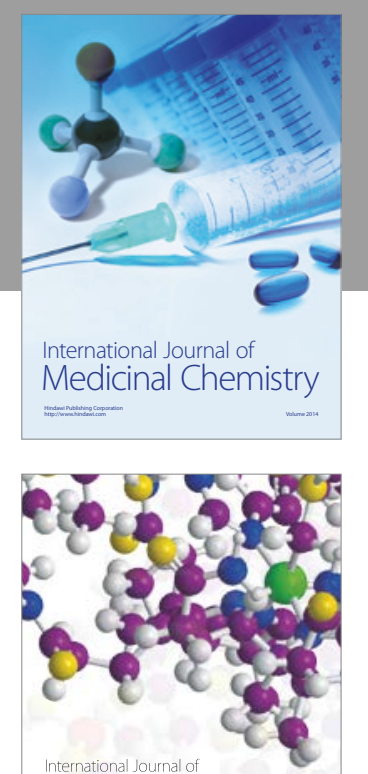

Carbohydrate Chemistry

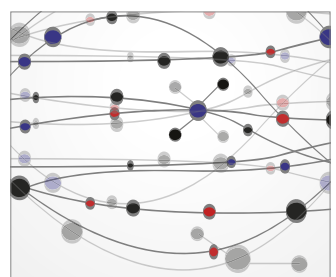

The Scientific World Journal
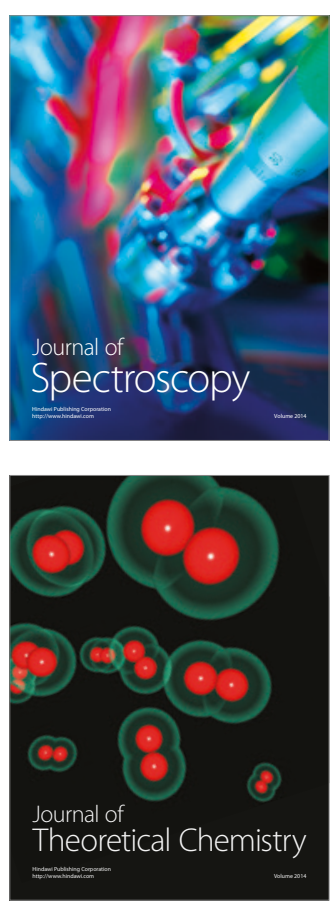
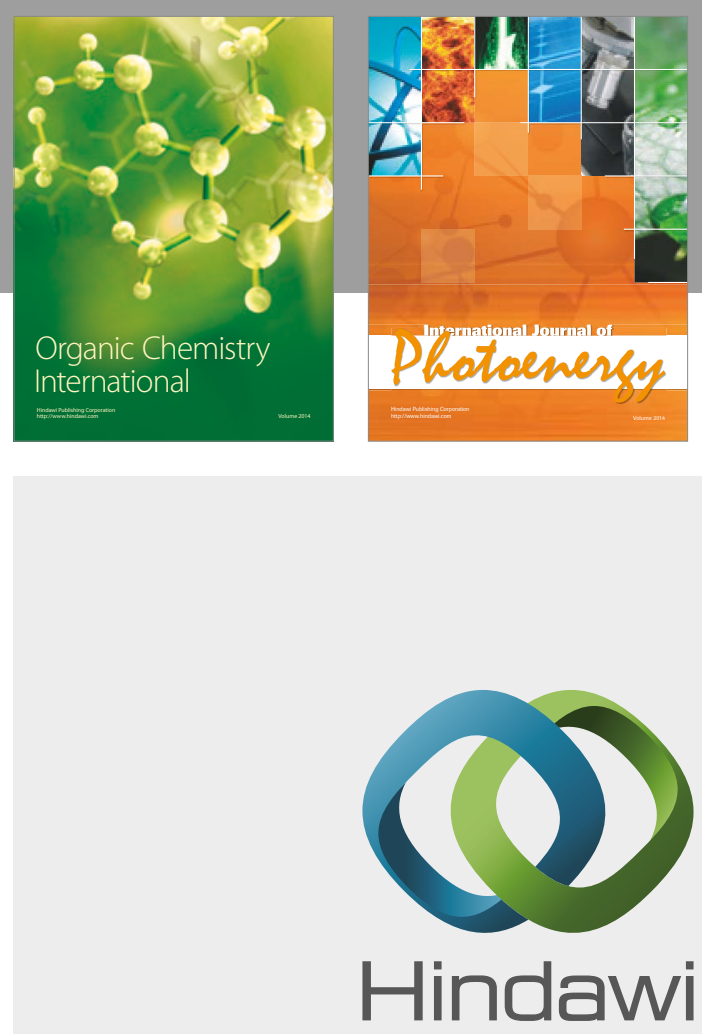

Submit your manuscripts at

https://www.hindawi.com

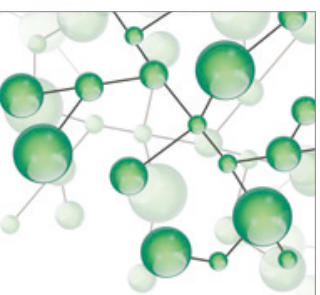

International Journal of

Inorganic Chemistry

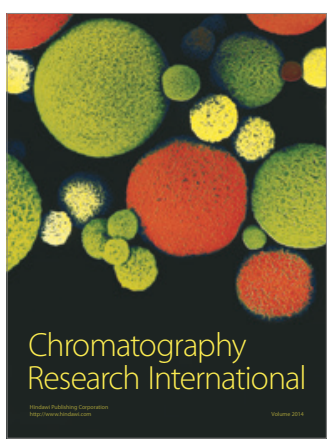

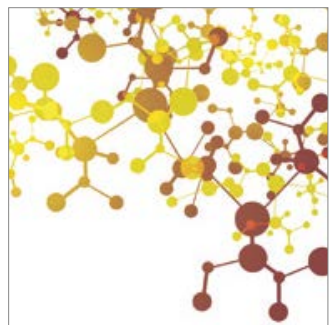

Applied Chemistry
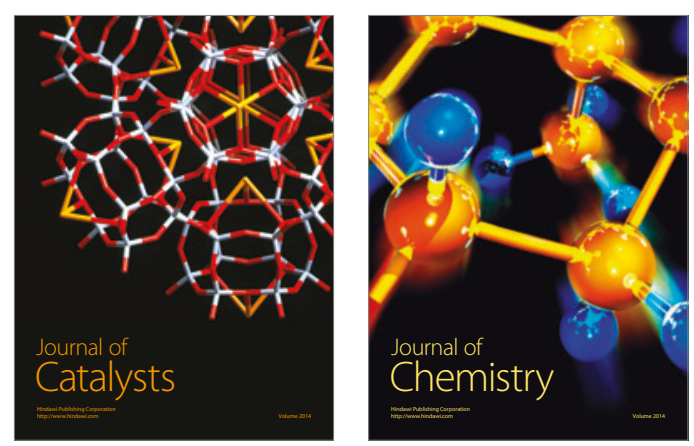
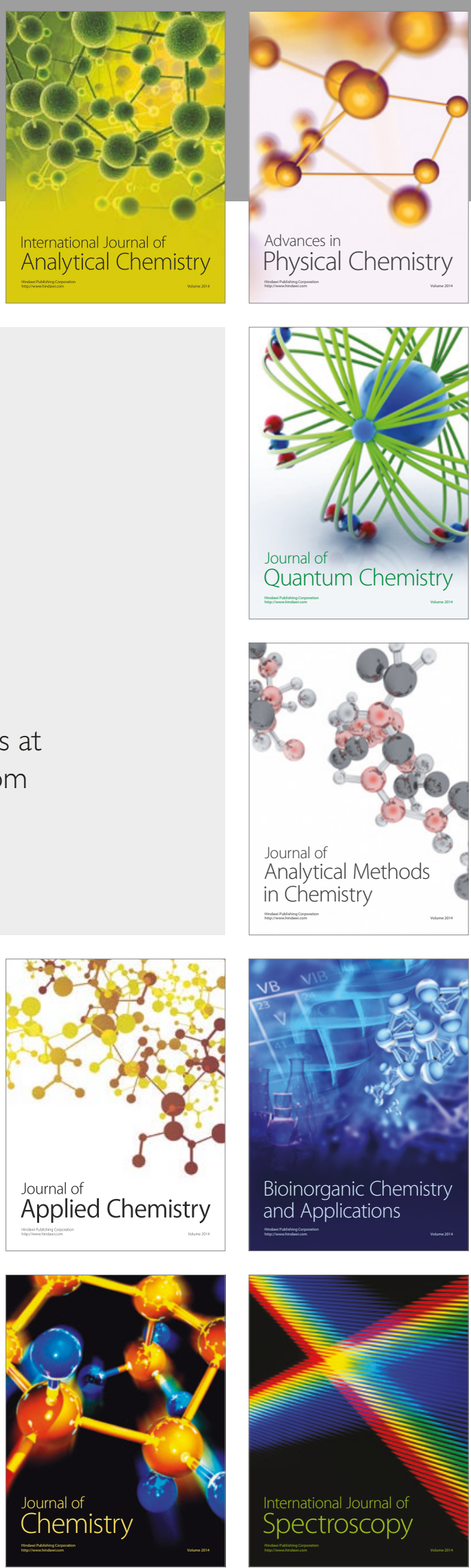